\title{
Elaboração de um catálogo comportamental de gato-do-mato-pequeno, Leopardus tigrinus (Schreber, 1775) (Carnivora: Felidae) em cativeiro
}

\author{
Márcio Cisterna Motta ${ }^{1} \&$ Nelio Roberto dos Reis ${ }^{2}$ \\ ${ }^{I}$ Instituto Maracajá para a Conservação dos Mamíferos Brasileiros, \\ São Vicente, SP, Brasil \\ ${ }^{2}$ Departamento de Biologia Animal e Vegetal, Universidade Estadual de Londrina - UEL, \\ CP 6001, CEP 86051-970, Londrina, PR, Brasil \\ ${ }^{3}$ Autor para correpondência: contato@maracaja.org.br
}

MOTTA, M.C. \& REIS, N.R. Elaboration of a behavioral catalog for the little spotted cat Leopardus tigrinus (Schreber, 1775) (Carnivora: Felidae) in captivity. Biota Neotrop., 9(3): http://www.biotaneotropica.org.br/ v9n3/en/abstract?article+bn00359032009.

\begin{abstract}
Considering that most species of Brazilian felids are threatened with extinction and poorly known, understanding their behavior is of special interest. This research aimed to create a behavioral catalog in captivity for the Little spotted cat Leopardus tigrinus, the smallest felid species from Brazil. A male and a female were studied at the private collection of wild animals of Klabin S.A. (Telemaco Borba, PR. $-24^{\circ} 12^{\prime} \mathrm{S}$ and $50^{\circ} 33^{\prime} \mathrm{W}$ ), in the mid Tibagi region, east-central Paraná State. From March to July, 2003, 40 hours of qualitative observations were carried out to define the categories and identify the behavior. The quantitative observations followed the Focal animal method (Altmann, 1974). They took place during three consecutive days and 11 observation periods (33 days), with 107.2 hours for the male and 42.4 hours for the female. Each session lasted 15 minutes, and started at the beginning of each hour (from 06:00 AM to 06:00 PM), with five-minute intervals between individual recording. The categories found were: moving (05 behavioral acts), still (06), body care (03), comfort (02), exploratory (04), marking (04), excretory (02), vocal (05), agonistic interactions (06), peaceful interactions (02), acts related to the acquisition of food (05) and reproductive acts (04). The catalog is a compilation of all behavioral acts of the species. There are many possibilities and perspectives for the use of this catalog. It could be an important tool to better understand the behavioral patterns and help the management and well being of the species in captivity.
\end{abstract}

Keywords: Leopardus tigrinus, little spotted cat, ethology, behavioral catalogue, captivity, small cats.

MOTTA, M.C. \& REIS, N.R. Elaboração de um catálogo comportamental de gato-do-mato-pequeno, Leopardus tigrinus (Schreber, 1775) (Carnivora: Felidae) em cativeiro. Biota Neotrop., 9(3): http://www.biotaneotropica.org.br/v9n3/pt/abstract?article+bn00359032009.

Resumo: Considerando que as espécies de felídeos brasileiros encontram-se ameaçadas de extinção, a coleta de dados comportamentais é de prioridade máxima. O objetivo desse trabalho foi elaborar um catálogo comportamental de Leopardus tigrinus em cativeiro, a menor espécie de felídeo do Brasil. Um macho e uma fêmea foram estudados no criadouro científico da Klabin S.A. (Telêmaco Borba, PR), região do médio Tibagi, centro-leste do Estado do Paraná. Entre março e julho de 2003 foram feitas 40 horas de observações qualitativas, para as definições das categorias e identificação dos atos comportamentais. As observações quantitativas seguiram o método "Animal Focal", e ocorreram entre agosto de 2003 a junho de 2004, com uma periodicidade de coleta de três dias corridos por mês, totalizando 11 períodos de observações (33 dias), com 107,2 horas para o macho e 42,4 horas para a fêmea. Cada sessão durou 15 minutos, iniciada sempre no começo de cada hora (das 06:00 às 18:00 horas), com intervalos de 5 minutos entre a observação dos indivíduos. As categorias encontradas foram locomoção (05 atos comportamentais), parado (06), cuidados corporais (03), conforto (02), exploratório (04), marcação (04), eliminação (02), vocalização (05), interações agonísticas (06), interações pacíficas (02), comportamentos relativos à obtenção de alimento (05) e comportamentos relacionados com a reprodução (04). Catálogo comportamental é catalogação dos comportamentos da espécie da espécie, ou seja, uma parcela dos possíveis comportamentos observados para tal. Existem várias possibilidades e perspectivas para sua utilização, sendo uma importante ferramenta para a compreensão dos padrões comportamentais, além de auxiliar estudos posteriores com Leopardus tigrinus.

Palavras-chave: Leopardus tigrinus, etologia, catálogo comportamental, cativeiro, pequenos felídeos. 


\section{Introdução}

Estudos comportamentais dos Felidae formam uma parte importante do desenvolvimento da Etologia, com os trabalhos de ontogenia e desenvolvimento locomotor de felídeos realizados por Lorenz \& Leyhausen (1973), e Leyhausen (1979), assim como as observações de Schaller (1972) sobre o comportamento de leões (Panthera leo) (Linnaeus, 1758) em vida livre, Mellen (1989) no trabalho sobre o comportamento reprodutivo de pequenos felídeos, e Alberts (2002) nas pesquisas de filogenia e evolução de felídeos.

Dentre as espécies brasileiras, Leopardus tigrinus é uma das menos conhecidas (Oliveira 1994). Poucos trabalhos exclusivamente sobre a espécie foram publicados, podendo destacar: Gardner (1971), enfocando dados ecológicos, Leyhausen \& Falkena (1966) e Quillen (1981), sobre manejo em cativeiro. No Brasil, Oliveira (1994) e Oliveira \& Cassaro (1999) publicaram informações gerais (biologia, ecologia, etologia e conservação) sobre os felídeos brasileiros, incluindo L. tigrinus. Resende et al. (2004) realizaram um estudo comportamental quantitativo em cativeiro, utilizando entre outras espécies de felídeos, L. tigrinus. Scatena et al. (2006) e Rampim et al. (2007), avaliaram o comportamento lúdico e predatório de L. tigrinus cativos, respectivamente. Genaro et al. (2007) publicaram recente estudo, envolvendo a fisiologia hormonal de gato doméstico (Felis cattus, Linnaeus, 1758) e felídeos neotropicais em cativeiro. É considerada uma das espécies mais raras encontradas em zoológicos (fora de sua área nativa), com cerca de $85 \%$ dos animais cativos encontrados no Brasil, onde a população ainda não é auto sustentável. Não existe quase nenhuma informação sobre exigências de habitat, áreas de vida, dinâmica populacional e coexistência com outros pequenos felídeos (Oliveira 1994, Oliveira \& Cassaro 1999).

É a menor espécie de felídeo brasileiro, freqüentemente confundido com gato-maracajá (Leopardus wiedii) (Schinz, 1821) (Eisenberg \& Redford, 1999). Apresenta porte e proporção corporal semelhante ao gato doméstico, com comprimento médio da cabeça e corpo de 49,1 cm, patas pequenas (proporcionais ao corpo) e cauda longa, em média com $26,4 \mathrm{~cm}$. O peso varia entre 1,75 e $3,5 \mathrm{~kg}$. As rosetas são grandes ou pequenas, abertas ou fechadas, mas, usualmente pequenas e abertas e em maior quantidade do que em $L$. wiedii (Emmons \& Feer 1997, Nowak 1999, Oliveira \& Cassaro 1999).

Segundo Oliveira (1994), habita os biomas Mata Atlântica, Cerrado, Pantanal, Campos do Sul e Amazônia. Sua distribuição geográfica vai do norte da Costa Rica ao nordeste da Argentina, habitando regiões com elevação de até 3.000 m. (Oliveira et al. 2008). Alimenta-se principalmente de pequenos mamíferos, aves e répteis (Oliveira 1994).

A espécie tem feito parte de coleções em zoológicos, porém, manejá-los tem sido um desafio. Freqüentemente permanece inativa ou escondida da visão do público, e quando ativa, pode demonstrar padrões aparentemente aberrantes ou locomoções estereotipadas (Shepherdson et al. 1993), além de se reproduzir de maneira inconsistente em muitas instituições (Mellen 1989). Devido a estas dificuldades, e somadas o comércio e caça ilegal, além da destruição do habitat (Nowak 1999, Oliveira 1994), L. tigrinus encontra-se tanto na lista vermelha dos animais ameaçados da IUCN (Oliveira 2008), quanto na lista das espécies da fauna brasileira ameaçada de extinção do IBAMA (Chiarello et al. 2008) como vulnerável (VU) e consta também no livro vermelho dos animais ameaçados de extinção do Paraná (Mikich \& Bérnils 2004). Considerando a ameaça de extinção, surgiu um interesse por parte dos Jardins Zoológicos e afins, tanto nacionais quanto internacionais, na sua manutenção e reprodução em cativeiro (Oliveira 1994, Nowak 1999). Sendo assim, a coleta de informação sobre esta espécie é de prioridade máxima (Mattern \&
McLennan 2000). O objetivo desse trabalho foi elaborar um catálogo comportamental de L. tigrinus em cativeiro.

\section{Metodologia}

\section{Descrição do local de estudo}

O criadouro científico de animais silvestres está inserido no Parque Ecológico (24 $12^{\prime} \mathrm{S}$ e $50^{\circ} 33^{\prime} \mathrm{O}$ ) de propriedade da Empresa Klabin S.A. (Fazenda Monte Alegre), e localizado na cidade de Telêmaco Borba, região do médio Tibagi, centro-leste do Estado do Paraná (Reis et al. 2002). Está registrado junto ao IBAMA desde 1989, sendo constituído por 53 recintos que abrigam 18 espécies de mamíferos, 48 espécies de aves, além de serpentário para cobras peçonhentas e não peçonhentas. O clima na região, segundo a classificação de Köppen (Trewartha \& Horn 1980), enquadra-se como subtropical sendo a temperatura média de inverno $16,3{ }^{\circ} \mathrm{C}$ e a de verão, $23,2{ }^{\circ} \mathrm{C}$. A precipitação média anual é de $1.478 \mathrm{~mm}$ (Reis et al. 2002).

\section{Espécimes estudados}

A espécie em estudo, em regime de cativeiro foi L. tigrinus (um macho e uma fêmea, Figura 1). O macho chegou ao criadouro em 1999, jovem encontrado órfão na cidade de Sapopema (PR). A fêmea foi apreendida adulta pela Polícia Florestal do Paraná, na cidade de Ivaiporã (PR) em 2001. Desde a chegada da fêmea, os dois exemplares foram pareados em recinto único.

\section{Instalações e manejo}

O recinto foi ambientado de acordo com os hábitos da espécie, com vários troncos, arbustos, pequenas plantas herbáceas e arbustivas. A exposição mede $40 \mathrm{~m}^{2}$ por $2 \mathrm{~m}$ de altura, com dois abrigos suspensos, feitos de madeira, uma caixa de areia para necessidades fisiológicas e um ponto de água corrente, com fornecimento de água constante. Há apenas um cambiamento, medindo $3 \mathrm{~m}^{2}$, por $2 \mathrm{~m}$ de altura. Os animais eram alimentados diariamente com carne bovina, frango ou rato de laboratório (morto), entre 16:00 e 18:00 horas. A limpeza do recinto era feita três vezes por semana.

\section{Coleta de dados}

Foram realizadas 40 horas de observações comportamentais, entre os meses de março a julho de 2003, com amostragem de todas as ocorrências (ad libitum, Altmann 1974), para as definições das categorias comportamentais e identificação dos atos comportamentais, iniciando a elaboração de um catálogo comportamental da espécie. A formulação de uma definição satisfatória de cada categoria comportamental é um processo lento e requer tal período de observação preliminar (Martin \& Bateson 1986).

Entre agosto de 2003 e junho de 2004, as observações seguiram o método "Animal Focal" (Altmann 1974), com registro contínuo, empregada para animais que podem ser facilmente observados, como em ambientes de cativeiro (Del-Claro 2002), com periodicidade de coleta de três dias consecutivos por mês, totalizando 11 períodos de observações (33 dias), com 107,2 horas de observação para o macho e 42,4 horas para a fêmea (a diferença na quantidade de horas ocorreu devido ao óbito da fêmea). Cada sessão durou 15 minutos, iniciada sempre no começo de cada hora (das 06:00 às 18:00 horas), com intervalos de 5 minutos entre a observação dos indivíduos. Os dados foram coletados com o auxílio de um gravador Microcassete Recorder Panasonic ${ }^{\circledR}$ RN-202, e, posteriormente, compilados para um livro de registros. Temperatura e umidade local também foram coletados.

Em todas as sessões de coleta de dados, o observador permanecia sempre no mesmo local e oculto, evitando que os indivíduos tivessem contato visual direto. Ao término das sessões, os comportamentos 

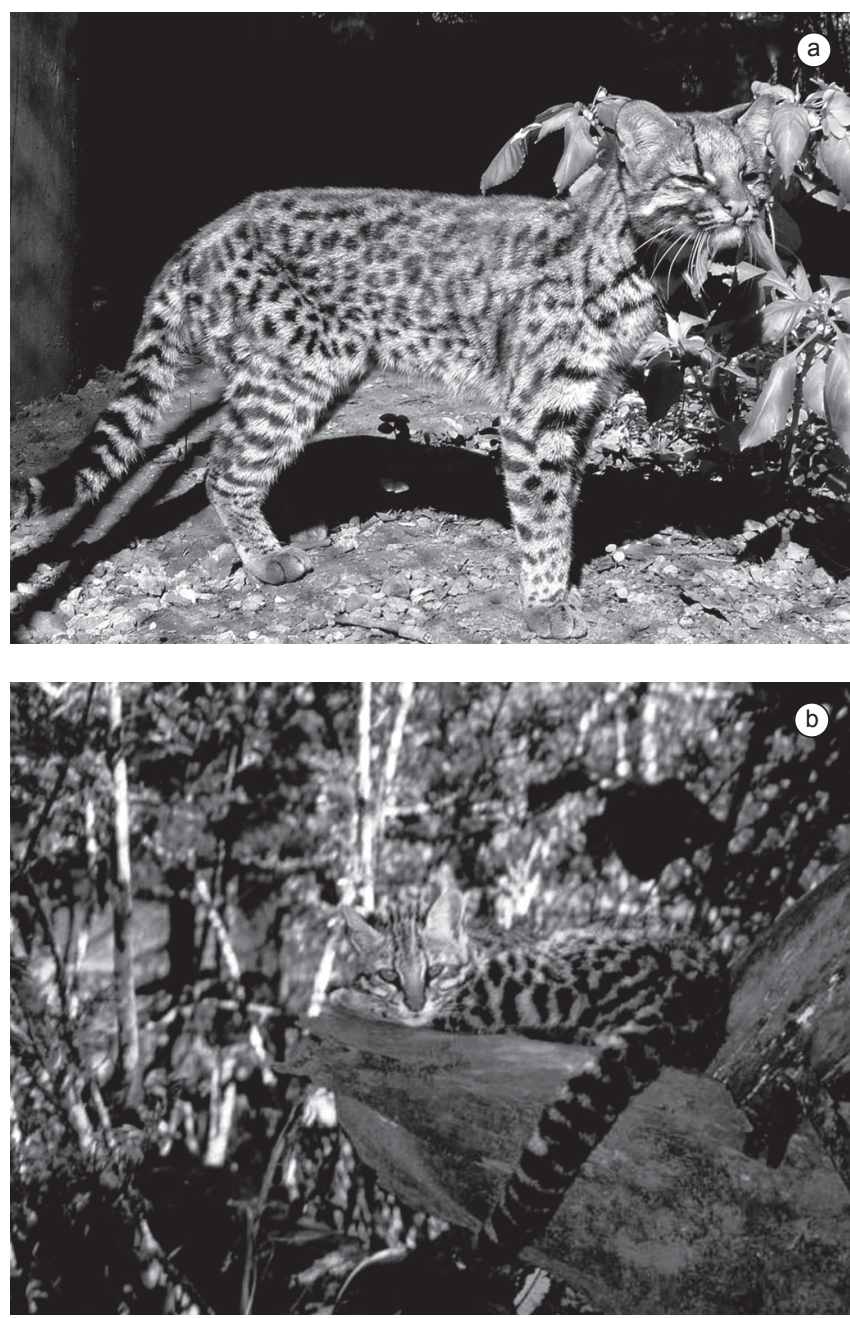

Figura 1. Exemplares de Leopardus tigrinus observados nos registros comportamentais. a) Macho e b) Fêmea.

Figure 1. Specimens of Leopardus tigrinus observed on behavioural records. a)Male and b) Female.

foram organizados de forma adequada numa lista, ou catálogo comportamental. Elaborado o catálogo comportamental, os atos comportamentais foram então agrupados em categorias, algumas dos quais correspondentes àqueles relatados por Schaller (1972) com Panthera leo (Linnaeus, 1758), Mellen (1989), que estudou comportamentos reprodutivos da subfamília Felinae, Weller \& Bennet (2001) com Leopardus pardalis (Linnaeus, 1758), e Cromberg et al. (1997) que elaborou o catálogo comportamental de Agouti paca (Linnaeus, 1766) em situação de cativeiro.

\section{Resultados}

O catálogo comportamental de L. tigrinus em cativeiro segue:

\section{Locomoção}

Comportamentos que envolvem o deslocamento do indivíduo.

1.1. Caminhar: movimentação quadrúpede alternada do(s) membro(s). Um dos membros sempre está em contato com o chão.

1.2. Correr: movimentação quadrúpede alternada dos membros. Os quatro membros podem não estar em contato com o chão ao mesmo tempo.
1.3. Saltar: o indivíduo, através de impulso fornecido pela flexão dos membros posteriores, move-se de um local para o outro, para cima ou para baixo, ou ainda em linha reta, sem ter contato com o substrato.

1.4. Escalar: movimento onde, com as garras protraídas, os quatro membros fazem o indivíduo locomover-se de um nível para outro mais elevado.

1.5. Locomoção repetitiva estereotipada: caminhada ou corrida num padrão repetitivo, sendo que uma mesma área é percorrida diversas vezes, num movimento de ir e vir, sem função aparente.

\section{Parado}

Comportamentos que não envolvem o deslocamento do indivíduo, podendo ou não este permanecer em estado de alerta.

\subsection{Em pé}

2.1.1. Em pé nos quatro membros: ficar em pé nos quatro membros podendo movimentar outras partes do corpo, como cabeça e cauda.

2.1.2. Em pé nos dois membros: ficar em pé nos dois membros posteriores, apoiando os anteriores ou não em alguma superfície podendo movimentar outras partes do corpo, como cabeça, cauda e os membros anteriores ou posteriores.

2.2. Deitado acordado: deitado com uma das partes laterais no substrato; Deitado com o ventre encostado no substrato e membros anteriores cruzados ou não, em posição semelhante a uma esfinge. Olhos abertos, em alerta.

2.3. Deitado dormindo: deitado com uma das partes laterais no substrato; Deitado com o ventre encostado no substrato e membros anteriores cruzados ou não, em posição semelhante a uma esfinge. Olhos fechados, não exibindo qualquer outro tipo de comportamento.

2.4. Sentado acordado: sentado com a região posterior (pélvica) no substrato. Membros posteriores flexionados, anteriores estendidos, com a região ventral não tocando o substrato. Olhos abertos, em alerta.

2.5. Sentado dormindo: sentado com a região posterior (pélvica) no substrato. Membros posteriores flexionados, anteriores estendidos, com a região ventral não tocando o substrato. Olhos fechados, não exibindo qualquer outro tipo de comportamento.

\section{Comportamentos relacionados com a obtenção de um conforto físico ou fisiológico}

\subsection{Cuidados corporais}

Movimentos do animal envolvidos com sua própria pelagem ou com outra parte do seu corpo.

3.1.1. Lambedura individual: refere-se ao ato de utilizar a língua para higienizar qualquer parte do próprio corpo.

3.1.2. Limpeza com membros anteriores: o indivíduo pode ter o auxílio dos membros anteriores para a higienização da região da cabeça, no sentido dos olhos para o nariz. Este ato pode se repetir várias vezes.

3.1.3. Coçar: utilizar os membros anteriores ou posteriores para esfregar a pelagem e pele.

3.1.4. Mordiscar: consiste em pequenas e contínuas mordidas na pelagem e pele.

\subsection{Conforto}

Movimentos do animal em que o resultado é um aparente relaxamento físico. 
3.2.1. Bocejar: o animal levanta a cabeça e abre a boca amplamente. Os dentes são expostos e os olhos fecham-se. A língua é protraída para um pouco além boca.

3.2.2. Espreguiçar: o indivíduo alonga ou estira toda ou parte do corpo, podendo estar em pé, deitado, ou sentado, ficando nessa posição por alguns segundos.

\subsection{Eliminação}

Atos comportamentais referentes às necessidades fisiológicas básicas de eliminação de um mamífero.

3.3.1. Urinar: ato de eliminar urina. Nesse caso, a cauda não está levantada, e o indivíduo urina no substrato (chão), com as pernas posteriores levemente flexionadas.

3.3.2. Defecar: ato de eliminar fezes. O indivíduo levanta a cauda, ficando com as pernas flexionadas durante o processo. Após a expulsão do último bolo fecal, vem na seqüência contração(ões) rápida(s) do ânus.

\section{Comportamentos que envolvem interações com o ambiente}

\subsection{Exploratório}

Atos comportamentais relacionados com a captação de informações sobre o ambiente.

4.1.1. Estar atento: caracteriza-se por olhar fixo em direção ao estímulo (objeto, indivíduo), e orelhas eretas, locomovendo-se (Caminhar e Locomoção repetitiva estereotipada) ou em posição de descanso (em pé, deitado e sentado).

4.1.2. Aproximar-se de algo ou de indivíduo de outra espécie: o indivíduo caminha, corre, salta ou escala em direção de um objeto, ou animal, dentro ou fora do recinto.

4.1.3. Flehmen: posição em pé, a cabeça levantada, o indivíduo abre a boca, mas não amplamente como num bocejo, embora os dentes fiquem expostos. $\mathrm{O}$ focinho é levantado e o nariz enruga-se, com olhos quase fechados. As orelhas permanecem relaxadas. A língua não fica protraída, e não ocorre nenhuma vocalização.

4.1.4. Cheirar: A boca geralmente permanece fechada. Nos substratos chão, grade, madeira, tronco, folhas, o animal direciona o focinho ao objeto, podendo estar se locomovendo (caminhar) ou em posição de descanso (em pé, em pé nas duas patas ou sentado). Ao cheirar fezes, urina, genitália (macho cheirando a fêmea) ou alimento, este é feito na posição Em pé. Quando o indivíduo cheira "ar", em posição em pé, não direciona o focinho para a um objeto específico, com a cabeça realizando movimentos curtos e lentos, para cima e para baixo. A boca pode estar semi-aberta.

\subsection{Marcação}

Comportamentos relacionados à marcação do ambiente.

4.2.1. Marcar com jato de urina: jatos de urina são lançados em superfícies verticais. A cauda é mantida ereta, podendo estar parado ou caminhando. Ao término, a cauda é mantida na posição vertical, logo em seguida é tremida a porção mediana-terminal da mesma.

4.2.2. Arranhar superfícies: sentado ou em pé, o indivíduo protrai as garras dos membros anteriores, e arranha superfícies num movimento de frente para trás, geralmente troncos de árvores.

4.2.3. Esfregar partes do corpo: o indivíduo fica em pé, esfregando a cabeça, bochecha, pescoço e parte da lateral do corpo, contra uma determinada superfície, em movimentos de ir e vir.

4.2.4. Esfregação de membros posteriores: $\mathrm{o}$ indivíduo fica em pé, esfregando as pernas posteriores uma contra a outra. Uma das pernas fica em contato com o chão, alternadamente. Durante o ato, o animal pode urinar.

\subsection{Obtenção de alimento}

Comportamentos do animal em relação a algum item alimentar seguido da ingestão.

4.3.1. Alimentar-se: o alimento é cortado com os dentes carniceiros, e mastigado com os molares, sendo depois ingerido. A posição geralmente é agachada ou a região mais próxima à cabeça fica abaixada, enquanto a região posterior do corpo está levantada.

4.3.2. Ingerir líquidos: a região anterior do corpo fica abaixada, enquanto a parte posterior está levantada. A língua carrega água até o interior da boca.

4.3.3. Carregar comida: o animal segura o alimento na boca (entre as mandíbulas), carregando-o para outro local, sendo ou não ingerido posteriormente.

4.3.4. Brincar com a comida: o animal carrega a comida pela boca e num dado momento a joga para cima, e então se esconde, ficando na posição agachada. Depois, salta em cima do alimento e morde, podendo segurá-lo com os membros anteriores. O comportamento pode se repetir várias vezes.

4.3.5. Lamber o alimento: o indivíduo lambe o alimento, mas não o ingere.

\section{Comportamentos que envolvem interações socias}

\subsection{Vocalização}

Emissões sonoras produzidas pelo aparelho bucal.

5.1.1. Rosnar: o indivíduo vocaliza com a boca fechada, numa série de sons de longa duração, graves e repetitivos.

5.1.2. Tipo "espirro": o indivíduo vocaliza com a boca aberta, numa série de sons semelhantes ao produzido por um espirro humano, não repetitivo.

5.1.3. Vibrar: a vocalização é feita com a boca fechada, numa série de sons de curta duração, agudos e repetitivos.

5.1.4. Miar: a vocalização é feita com a boca aberta, produzindo um som agudo sem interrupções, semelhante ao gato doméstico (Felis cattus, Linnaeus, 1758).

5.1.5. Grito copulatório: vocalização realizada pela fêmea. A boca permanece aberta, produzindo som baixo sem interrupção.

\subsection{Interações agonísticas}

Envolvem situações de conflito entre dois animais da mesma espécie, ocorrendo ou não contato físico.

5.2.1. Eriçar pêlos: os pêlos da região do dorso e pescoço ficam eriçados.

5.2.2. Dar patada em outro animal: o indivíduo golpeia com os membros anteriores ou posteriores outro animal.

5.2.3. Morder: o indivíduo morde outro, perfurando ou não a pele, ou morde algum objeto.

5.2.4. Perseguir indivíduo: corrida curta ou longa atrás de outro indivíduo, podendo ocorrer saltos ou escaladas.

5.2.5. Arquear as costas: costas são arqueadas, podendo ou não ocorrer salto para o lado, mas sempre em pé com os membros esticados e cauda ereta. Há eriçamento evidente dos pêlos do dorso e pescoço, dentes caninos e incisivos à mostra, orelhas abaixadas e cauda em direção ao chão. Pode ocorrer vocalização do tipo "espirro".

\subsection{Interações pacíficas}

Contatos físicos com outros indivíduos sem a ocorrência de comportamentos agonísticos.

5.3.1. Lamber socialmente: o indivíduo lambe outro, podendo intercalar com lambedura individual.

5.3.2. Cheirar socialmente: é cheirada qualquer região de outro indivíduo. 


\subsection{Reprodução}

São os comportamentos relacionados com a atividade sexual.

5.4.1. Cópula: o macho se aproxima da fêmea, monta com auxílio dos membros anteriores e depois os posteriores, e morde a nuca da fêmea. A fêmea responde ao aperto na nuca, assumindo na maioria das vezes a postura de lordose, movendo a cauda para um dos lados. Pode haver locomoção da fêmea (caminhar na posição de lordose). $\mathrm{O}$ macho então inicia a intromissão do pênis. Ocorre um grito da fêmea (grito copulatório) e a ejaculação. Em seguida, expulsa o macho de cima dela com patadas, rosnadas, e perseguições, e após isso, começa a rolar nas costas.

5.4.2. Tentativa de cópula: o macho se aproxima da fêmea, monta com auxílio dos membros anteriores e depois os posteriores, e morde a nuca da fêmea. A fêmea responde ao aperto na nuca expulsando o macho de suas costas, com patadas, rosnadas, e perseguições. Não há intromissão do pênis e grito copulatório.

5.4.3. Rolar nas costas: a fêmea posiciona-se com o dorso no substrato, encolhe os membros, e inicia movimentos ondulatórios com as costas, esfregando esta parte do corpo no substrato.

5.4.4. Lordose: quando em pé nas quatro patas, a fêmea abaixa a parte anterior, enquanto eleva a posterior, com a cauda de lado.

\section{Discussão}

Estudando o comportamento de animais cativos não se pode ter certeza de quanto esse foi alterado pelas condições anormais do confinamento. Para Lorenz (1995), uma das vantagens é observar perturbações trazidas pelas condições artificiais do ambiente, como por exemplo, a diminuição da intensidade exibida em certos movimentos instintivos.

Embora L. tigrinus conste nas listas de animais ameaçados de extinção, segundo órgãos nacionais e internacionais (MMA, 2003 e IUCN, 2008, respectivamente), os dados comportamentais específicos existentes na literatura são escassos, e um catálogo comportamental não tinha sido preparado. Mellen (1989) estudou 16 espécies de pequenos felídeos, onde L. tigrinus foi excluído.

A categoria locomoção foi a mesma proposta por Mellen (1989), embora no presente trabalho os atos tiveram um maior detalhamento na descrição, além de ter sido acrescentado locomoção repetitiva estereotipada, que mesmo sendo considerada um comportamento aberrante e freqüente por Shepherdson et al. (1993) e colocado à parte por Mellen (1989), consideramos que este se encaixa na definição da categoria, sendo que não procuramos apontar as causas, e sim descrever como são realizados.

Segundo Shepherdson et al. (1993), pequenos felídeos em cativeiro tendem a se tornarem inativos, gastando grandes quantidades de tempo fora da visão ou sonolentos. Diferentemente dos catálogos propostos por Mellen (1989), Cromberg et al. (1997) e o trabalho de Schaller (1972), a categoria em que os indivíduos não estão em movimento foi denominada parado, ao invés de descanso. Acredita-se que a última indica indivíduos relaxados ou desatentos, quando isto não é verdade para todos os atos incluídos nesta categoria. Quando acordados, notaram-se claramente os mesmos em estado de alerta (Mellen 1989), ou seja, estavam utilizando o sentido da visão para observar as redondezas. A denominação "parado" descreve apenas o estado de atividade, não relacionando outros atos comportamentais à posição dos mesmos.

Felídeos possuem um cuidado especial com sua pelagem, notavelmente maior do que, por exemplo, em canídeos (Darwin, 2000). Durante todo o dia, sessões de cuidados corporais foram freqüentes e geralmente ocorreram em conjunto, mas sem sequiência estabelecida. Apenas um dos atos foi realizado separadamente, coçar. Uma freqüência maior de lambedura dos membros anteriores e cabeça ocorreu após a alimentação. Embora Mellen (1989) e Weller \& Bennet (2001) utilizem o termo auto-manutenção para esta categoria, adotamos a definição de Cromberg et al. (1997), o que nos parece mais adequado com relação aos outros comportamentos inseridos.

A categoria comportamental conforto foi criada para acomodar bocejo e espreguiçar, que executam para um aparente relaxamento corporal. O bocejo parece não ser um ato agonístico intra-específico, como relatado para alguns primatas por Darwin (2000). Em nenhum momento foi direcionado para outro, ou depois de alguma situação de estresse. Ocorreu geralmente logo após acordarem ou quando os mesmos estavam parados acordados. Espreguiçar foi observado sempre que os indivíduos estavam parados em pé, deitados e sentados, e parece não haver relação com qualquer estímulo para que o mesmo possa acontecer.

Herbers (1981) relata que a maioria dos animais em seu ambiente natural gasta uma parte de sua atividade diária explorando o ambiente. Segundo Powell (1997), na natureza, felídeos encontram uma ampla variedade de odores, sons, visões, gostos e texturas, e o animal depende de informações sensoriais para sua sobrevivência. Desses sentidos, o mais utilizado é o olfato (Mellen 1989). No presente estudo, embora não tenham sido realizadas quantificações, confirmam-se as afirmações supracitadas, pois dentro da categoria exploratório, o ato cheirar foi muito observado durante as movimentações, e até mesmo quando estavam parados. No recinto, devido a grande quantidade de plantas e troncos de árvores colocados, haviam inúmeros locais para serem marcados, e também onde restos de alimentos ficarem temporariamente ocultos. Muitas vezes, os indivíduos foram observados cheirando locais específicos pela manhã (08:00 e 10:00 horas), e após instantes os mesmos iniciavam a ingestão de sobras alimentares provavelmente fornecidas no dia anterior, distante do local onde o tratador oferece a dieta. Outro ato relacionado foi flehmen, presente em grande parte da família Felidae (Schaller 1972), que tem como uma das funções verificar, através da captação de moléculas presentes na urina (feromônios), a condição estral das fêmeas da espécie (Oliveira et al. 2001). O ato investigar foi também freqüentemente observado, podendo ser devido a esta espécie não ser topo de cadeia alimentar, servindo de presa para outros carnívoros (Mellen 1997). Assim, ela necessita ficar mais alerta, à procura de eventuais predadores. Ao contrário, o ato seguir é, na realidade, a expressão do comportamento de predador, e foi direcionado, na maioria das vezes, para aves (comumente Crotophaga anii - anú preto) que pousavam na parte superior do recinto, composta de tela. Este comportamento também foi relatado por Mellen (1991b, 1998) com outros felinos.

$\mathrm{O}$ ato comportamental de marcação mais característico em felídeos é jato de urina (Mellen 1991b). Foi o mais comum durante as observações, mostrando locais específicos de marcação (troncos e plantas). Arranhar com as garras é provavelmente um sinal visual, indicando fronteiras do território de um indivíduo (Schaller 1972). Era também realizado em locais onde já haviam sido feitas marcações, além de localizarem-se, em sua grande maioria, próximo aos limites do recinto. Para Mellen (1991b) esfregar várias partes do corpo contra objetos para marcação de cheiro é outra das características dos felídeos encontradas em L. tigrinus, como esfregaço de tronco e membros posteriores, sendo que estes possuem glândulas nessas regiões, e que geralmente esfregam o que já foi marcado pela urina. Esses comportamentos foram realizados com freqüência diária por ambos os sexos, corroborando com as afirmações de Mellen (1989) sobre a territorialidade de pequenos felídeos.

Considerou-se na categoria eliminação, os atos relacionados à excreção de substâncias não aproveitadas pelo corpo (Schmidt-Nielsen 2002). Urinar foi observado apenas uma única vez, sendo executado pela fêmea. A justificativa para tão baixa ocorrência deve-se à alta 
frequiência em que os indivíduos utilizam a urina como forma de marcação (Mellen 1991b). Já defecação foi observada várias vezes, e realizada sempre no mesmo local (caixa de areia). Darwin (2000) sugere outros comportamentos, como vomitar, visto em felídeos e outros animais, mas no presente estudo não foram observados.

Encontros agonísticos são evitados na maioria das vezes na natureza através de marcas visuais, olfativas e auditivas (Ewer 1973), principalmente em espécies de hábitos solitários. A agressividade é comum em todos os animais (Lorenz 1995), embora pronunciada em animais cativos (Grier 1984), devido a estes não poderem se esquivar de conspecíficos todo o tempo. Durante o período de observação, atos agonísticos se concentraram na hora em que o alimento era oferecido, com o macho muitas vezes impedindo a fêmea de ter acesso. Nessa ocasião eriçar pêlos, costas arqueadas, morder, perseguir e patadas, foram observados, sem uma seqüência, nem obrigatoriedade da presença dos três últimos supracitados durante a situação. Houve também encontros agonísticos quando a fêmea estava no pré-estro e estro, onde, nessa condição, era a mesma quem atacava o macho. Eriçar pêlos e arquear, consideradas por Ewer (1973) como posturas de ameaça ocorreu sempre antes do contato físico entre os indivíduos.

A vocalização é um importante meio de expressão nos felídeos (Case 2003). Nas observações, foram distinguidos cinco tipos de vocalização, embora Peters (1991) defina 12 diferentes para a maioria dos felídeos. O número de vocalizações observadas pode estar subestimado, devido às diferenças não serem percebidas sem a utilização de instrumentos especializados. Das cinco, três são associadas por Mellen (1989), Case (2003) e Ewer (1973) a comportamentos agonísticos intra e interespecíficos, e as observações comprovam e confirmam os autores. São rosnar, assobiar e vibrar. O miar foi observado duas vezes na fêmea, mas, aparentemente, sem motivo algum. Petersen (1979) relaciona o miar de fêmeas de L. wiedii com o período em que as mesmas estão no cio. O ronronar, que Case (2003) aponta como um indicador de satisfação, além de ser um importante método de comunicação social, foi observado algumas vezes, quando o indivíduo se esfregava em troncos ou na tela que reveste o recinto. No presente trabalho, esse ato não foi estudado com o objetivo de confirmar a afirmação supracitada.

Comportamentos alimentares estão relacionados à obtenção do alimento, mesmo em ambientes cativos. Na natureza, Shepherdson et al. (1993) relata que pequenos felídeos caçam várias vezes ao dia, por meio de duas estratégias: patrulhar o território até encontrar a presa, ou ficar na espreita até a mesma aparecer. No cativeiro, o alimento é fornecido uma vez ao dia com horários determinados. Sunquist \& Sunquist (1991) apontam que, devido à quebra da seqüência predatória, alterações comportamentais podem ocorrer, e Leyhausen apud Lorenz (1995) demonstrou que para compensar a ausência dos estímulos para a caça, os felídeos tendem a descarregar os padrões motores não usados em forma de brincadeira com o alimento. A ingestão de líquidos foi observada em algumas ocasiões, e devido ao horário de oferta de alimento estar próximo ao anoitecer, não houve a possibilidade de constatar as observações de Theobald (1986), que afirma que felídeos ingerem mais água após as refeições. Para todos os alimentos oferecidos (carne bovina, frango e rato branco), o comportamento carregar comida foi observado, e, na maioria das vezes, o pedaço era retirado do local em que era oferecido, e então consumido.

Para Mellen (1989), os comportamentos reprodutivos dos pequenos felídeos parecem ser similares entre as espécies. O padrão da seqüência da cópula ou tentativa de L. tigrinus é o mesmo descrito em seu trabalho para outras espécies. Apenas duas cópulas foram observadas, enquanto que as tentativas foram muito mais freqüentes. Isto pode estar relacionado ao fato de que as observações possam ter ocorrido no pré ou pós-estro, quando a fêmea, não tolera a cópula.
Rolar nas costas e lordose estão associadas ao estro, e quando as fêmeas estão em cio à freqüência dos atos é maior (Moreira 2001). Estes atos só foram observados juntamente com cópula ou tentativa, indicativos de que a fêmea estava em estro. Durante o trabalho houve um nascimento, no mês de outubro de 2003. O neonato foi devorado pela mãe aproximadamente dois dias após o nascimento, sem causa definida.

\section{Considerações Finais}

Os resultados obtidos com o presente estudo mostram uma parte significativa do comportamento de L. tigrinus em cativeiro. É possível que muitos comportamentos não tenham sido observados ou os indivíduos não o expressaram, independente do motivo. Por esta razão, um trabalho com maior tempo de observação e amostragem com mais exemplares se faz necessário para transpor os resultados para a espécie como um todo, pois há muito ainda para ser estudado. Mas os atos comportamentais registrados são certamente de grande valia para o aprimoramento do conhecimento sobre a espécie, e para o manejo da mesma em ambientes cativos.

Observou-se que os indivíduos estudados mostraram-se muitas vezes agressivos entre si, e uma solução que pode ser adotada é a separação de indivíduos do sexo oposto durante o período de anestro, sendo o casal formado apenas na época de reprodução. Este procedimento deveria passar a ser adotado pelas instituições mantenedoras da espécie em cativeiro. Outra recomendação seria o oferecimento da alimentação em dois ou três horários aleatórios diariamente, para tentar minimizar comportamentos estereotipados ligados ao sistema de alimentação. Espera-se que novos estudos possam surgir para complementar e auxiliar a conservação, in-situ e ex-situ de L. tigrinus e das outras espécies de pequenos felídeos brasileiros.

\section{Agradecimentos}

À Klabin S.A. por ceder o espaço e os animais inseridos no estudo, além dos técnicos que exercem suas atividades no Criadouro Científico, especialmente Vlamir José Rocha, Sérgio Adão Filipaki e o tratador Celso. Ao professor Dr. Hernán Fandiño Marino pelas valiosas colaborações durante o decorrer da pesquisa.

\section{Referências Bibliográficas}

ALBERTS, C.C. 2002. Evolução da socialidade em felinos: contribuição da filogenia. In Anais do Encontro Anual de Etologia. Sociedade Brasileira de Etologia, Natal.

ALTMANN, J. 1974. Observational study of behavior: sampling methods. Behavior. 49(3):227-265.

CASE, L.P. 2003. The cat: its behavior, nutrition and health. Iowa State Press, Iowa.

CAT SPECIALIST GROUP. 2008. Leopardus tigrinus. IUCN, Switzerland. http://www.iucnredlist.org/details/11510/0 (último acesso em 10/06/2009)

CHIAREllo, A.G., AGUiAR, L.M.S., CERQUEIRA, R., MELO, F.R., RODRIGUES, F.H.G. \& SILVA, V.M. 2008. Mamíferos ameaçados de extinção no Brasil. In Livro vermelho da fauna brasileira ameaçada de extinção (A.B.M. Machado, G.M. Drummond \& A.P. Paglia, eds.). Fundação Biodiversitas, Belo Horizonte.

CROMBERG, V.U., SABATINI, V. \& PARANHOS da COSTA, M.J.R. 1997. O comportamento da paca (Agouti paca) em cativeiro. In Anais do Encontro Anual de Etologia. Sociedade Brasileira de Etologia, São Carlos, p. 223-239.

DARWIN, C.R. 2000. A expressão das emoções nos homens e nos animais. 1 reimpressão. Editora Schwarcz, São Paulo.

DEL-CLARO, K. 2002. Uma orientação ao estudo do comportamento animal. 1 ed. Livraria Conceito, Uberlândia. 
EISENBERG, J.F. \& REDFORD, K.H. 1999. Mammals of the neotropics: the central neotropics. University of Chicago Press, Chicago.

EMMONS, L.H. \& FEER, F. 1997. Neotropical rainforest mammals: a field guide. 2 ed. The University of Chicago Press, Chicago.

EWER, R.F. 1973. The Carnivores. Cornell University Press, New York.

GARDNER, A.L. 1971. Notes on the little spotted cat, Felis tigrina oncilla, Thomas, in Costa Rica. In. J. Mammal. 52(2):464-465.

GENARO, G., MORAES, W., SILVA, J.C.R., ADANIA, C.H. \& FRANCI, C.R. 2007. Plasma hormones in neotropical and domestic cats undergoing routine manipulations. Research in Veterinary Science. 82(2):263-270.

GRIER, J.W. 1984. Biology of animal behavior. Times Mirror; Mosby College Publishing, St. Louis.

HERBERS, J.M. 1981. Time resources and laziness in animals. Oecologia. 49(2):252-262.

LEYHAUSEN, P. 1979. Cat Behaviour. Garland STPM, New York.

LEYHAUSEN, P. \& FALKENA, M. 1966. Breeding the Brazilian ocelot-cat Leopardus tigrinus in captivity. Int. Zoo Yearb. 6:176-182.

LORENZ, K. 1995. Os fundamentos da Etologia. Edunesp, São Paulo.

LORENZ, K. \& LEYHAUSEN, P. 1973. Motivation of human and animal behavior: an ethological view. Van Nostrand Reinhold, New York.

MARTIN, P. \& BATESON, P. 1986. Measuring Behaviour. Cambrigde University Press, Cambridge.

MATTERN, M.Y. \& MCLENNAN, D. 2000. Phylogeny and speciation of felids. Cladistics. 16(2):232-253.

MELLEN, J.D. 1989. Reproductive behavior of small captive exotic cats (Felis spp.). Tese de Doutorado, Universidade da Califórnia, Davis.

MELLEN, J.D. 1991a. Cat behaviour. In Great cats (J. Seidensticker \& S. Lumpkin, eds.). Dodale Press, Pennsylvania, p. 68-79.

MELLEN, J.D. 1991b. Little known cats. In Great cats (J. Seidensticker \& S. Lumpkin, eds.). Dodale Press, Pennsylvania, p. 170-183.

MELLEN, J.D. 1997. Minimum husbandry guidelines for mammals: small felids. American Association of Zoos and Aquariums, USA.

MELLEN, J.D., HAYES, M.P. \& SHEPHERDSON, D.S. 1998. Captive environments for small felids. In Second nature: environments for captive animals (D.S. Shepherdson, J.D. Mellen \& M. Hutchins, eds.). Smithsonian Institution Press, Washington, p.184-201.

MOREIRA, N. 2001. Reproduction in small female felids. In Biology, medicine and surgery of south American wild animals (M.E. Fowler \& Z.S. Cubas, eds.). Iowa State University Press, Iowa, p. 301-307.

NOWAK, R.M. 1999. Walker's mammals of the world. 6 ed. John Hopkins University Press, Baltimore, Maryland.

OLIVEIRA, T.G. 1994. Neotropical cats: ecology and conservation. EDUFMA, São Luis.

OLIVEIRA, T.G. \& CASSARO, K. 1999. Guia de identificação dos felinos brasileiros. 2 ed. Sociedade de Zoológicos do Brasil, São Paulo.

OLIVEIRA, T.G., EIRIZIK, E. \& CRAWSHAW, P.G. 2001. Order Carnivora. In Biology, medicine and surgery of south American wild animals (M.E. Fowler \& Z.S. Cubas, eds.). Iowa State University Press, Iowa, p. 291-309.
OLIVEIRA, T., EIRIZIK, E., SCHIPPER, J., VALDERRAMA, C., LEITEPITMAN, R. \& PAYAN, E. 2008. Leopardus tigrinus. In IUCN Red list of threatened species. Version 2009. IUCN, Cambridge. http://www. iucnredlist.org (último acesso em 10/06/2009).

PARANÁ. 2004. Lista vermelha de animais ameaçados de extinção no Estado do Paraná. Secretaria do Meio Ambiente, Curitiba.

PETERS, G. 1991. Vocal communication in cats. In Great cats (J. Seidensticker \& S. Lumpkin, eds.). Dodale Press, Pennsylvania, p. 100-114.

PETERSEN, M.K. 1979. Behavior of the margay. Carnivore. 2:69-76.

POWELL, K.E. 1997. Environmental enrichment programme for ocelots at north Carolina zoological park, Asheboro. Int. Zoo. Yearb. 35:217-224.

QUILLEN, P. 1981. Hand rearing the little spotted cat or oncilla (Felis tigrinus). Int. Zoo. Yearb. 2:240-242.

RAMPIM, L.E., MOTTA, M.C., SCATENA, T.G., MARQUES, M.C., CASSARO, K., COUTINHO, P.H., GENARO, G. \& OLIVEIRA, T.G. 2007. Dados quantitativos e qualitativos acerca do comportamento predatório de Leopardus tigrinus (Schreber, 1775) na Fundação Parque Zoológico de São Paulo. In Anais do Congresso Todos pela Conservação. Sociedade de Zoológicos do Brasil, São Paulo.

REIS, N.R., PERACCHI, A.L. \& LIMA, I.P. 2002. Morcegos da bacia do Rio Tibagi. In A bacia do Rio Tibagi (M. Medri, E. Bianchini, O.A. Shibatta \& J.A. Pimenta, eds.). EDUEL, Londrina, p. 251-270.

RESENDE, L., REMY, G.L. \& ANDRIOLO, A. 2004. Comportamento de Pequenos Felinos Neotropicais em Cativeiro. In Anais do Encontro Anual de Etologia. Sociedade Brasileira de Etologia, Campo Grande.

SCATENA, T.G., RAMPIM, L.E., MOTTA, M.C., MARQUES, M.C., CASSARO, K. \& OLIVEIRA, T.G. 2006. Comportamento lúdico de Leopardus tigrinus (Schreber, 1775) frente à alimentação. In Anais do Encontro Anual de Etologia. Sociedade Brasileira de Etologia, Brasília.

SCHALLER, G.B. 1972. The Serengeti Lion: a study of predator-prey relations. University of Chicago Press, Chicago.

SCHMIDT-NIELSEN, K. 2002. Fisiologia animal: adaptação e meio ambiente. 5 ed. Santos Livraria Editora, São Paulo.

SHEPHERDSON, D., CARLSTEAD, K., MELLEN, J. \& SEIDENSTICKER, J. 1993. The influence of food presentation on the behavior of small cats in confined environments. Zoo Biology. 12:203-216.

SUNQUIST, F. \& SUNQUIST, M. 1991. Ocelots and servals. In Great cats (J. Seidensticker \& S. Lumpkin, eds.). Dodale Press, Pennsylvania, p. 156-161.

THEOBALD, J. 1986. Felidae. In Zoo and wild animal medicine (M.E. Fowler, ed.). W.B. Saunders Company, Philadelphia, p. 650-667.

TREWARTHA, G.T. \& HORN, L.H. 1980. An introduction to climate. 5 ed. McGraw-Hill, New York.

WELLER, S.H. \& BENNETT, C.L. 2001. Twenty-four hour activity budgets and patterns of behavior in captive ocelots (Leopardus pardalis). Appl. Anim. Behav. Sci. 71:67-79. 